\title{
Operations of a
}

Radioisotope-Based Propulsion System Enabling CubeSat Exploration of the Outer
Planets

\section{SpaceOps 2014 13th International Conference on Space Operations}

U.S. Department of Energy

National Laboratory

operated by

Battelle Energy Alliance

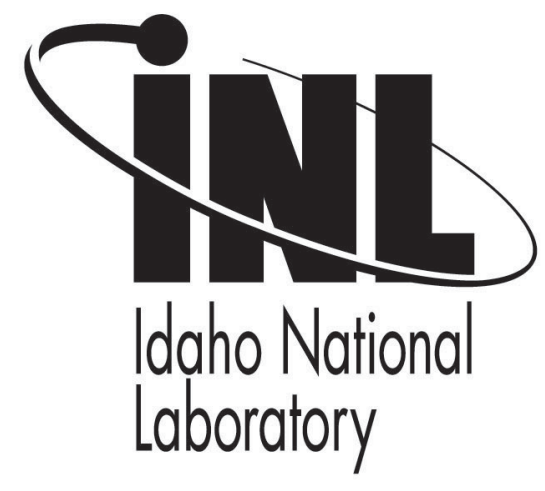

Steve Howe

Nathan Jerred

Troy Howe

Adarsh Rajguru

This is a preprint of a paper intended for publication in a journal or proceedings. Since changes may be made before publication, this preprint should not be cited or reproduced without permission of the author. This document was prepared as an account of work sponsored by an agency of the United States Government. Neither the United States Government nor any agency thereof, or any of their employees, makes any warranty, expressed or implied, or assumes any legal liability or responsibility for any third party's use, or the results of such use, of any information, apparatus, product or process disclosed in this report, or represents that its use by such third party would not infringe privately owned rights. The views expressed in this paper are not necessarily those of the United States Government or the sponsoring agency. 


\title{
Operations of a Radioisotope-based Propulsion System Enabling CubeSat Exploration of the Outer Planets
}

\author{
Dr. Steve Howe, Nathan Jerred and Troy Howe ${ }^{1}$ \\ Center for Space Nuclear Research, Idaho Falls, Idaho, 83401, USA \\ Adarsh Rajguru ${ }^{2}$ \\ University of Southern California, Los Angeles, CA, 90089-1192, USA
}

\begin{abstract}
Exploration to the outer planets is an ongoing endeavor but in the current economical environment, cost reduction is the forefront of all concern. The success of small satellites such as CubeSats launched to Near-Earth Orbit has lead to examine their potential use to achieve cheaper science for deep space applications. However, to achieve lower cost missions; hardware, launch and operations costs must be minimized. Additionally, as we push towards smaller exploration beds with relative limited power sources, allowing for adequate communication back to Earth is imperative. Researchers at the Center for Space Nuclear Research are developing the potential of utilizing an advanced, radioisotope-based system. This system will be capable of providing both the propulsion power needed to reach the destination and the additional requirements needed to maintain communication while at location. Presented here are a basic trajectory analysis, communication link budget and concept of operations of a dual-mode (thermal and electric) radioisotope-based propulsion system, for a proposed mission to Enceladus (Saturnian icy moon) using a $6 \mathrm{U}$ CubeSat payload. The radioisotope system being proposed will be the integration of three sub-systems working together to achieve the overall mission. At the core of the system, stored thermal energy from radioisotope decay is transferred to a passing propellant to achieve high thrust - useful for quick orbital maneuvering. An auxiliary closed-loop Brayton cycle can be operated in parallel to the thrusting mode to provide short bursts of high power for high data-rate communications back to Earth. Additionally, a thermal photovoltaic (TPV) energy conversion system will use radiation heat losses from the core. This in turn can provide the electrical energy needed to utilize the efficiency of ion propulsion to achieve quick interplanetary transit times. The intelligent operation to handle all functions of this system under optimized conditions adds to the complexity of the mission architecture.
\end{abstract}

\section{Motivation}

$\mathrm{T}$ HERE are several areas that led to the inspiration of this exploration probe. First high launch costs limits the number of missions selected, especially relative to our current budget. Exploration to the outer planets has been limited to high budget missions. Limited budgets make large missions more difficult to fund. Hence the motivation is to develop technologies enabling reliable, compact exploration platforms, which will be able to achieve more science-per-dollar.

These platforms should is also required to be long-lived and long-ranged mobile platform in order to enable a long duration flight path to reach targets in outer planet regime. The primary motivation is to develop an off-the-shelf propulsion system that can be applied to multiple missions and payloads, with minimal changes to overall concept design. The focussed group will be smaller satellites in the range of micro-satellite scale payload. This will in turn enable affordable deep space exploration. Another crucial motivation is to explore the possibility of using small launch vehicles (less than $1000 \mathrm{~kg}$ to LEO) for carrying the dual mode propulsion system including the payload to LEO. After that the dual-mode propulsion system can be used as a kick motor to escape Earth's sphere of influence into a trajectory to outer planets. Hence teasing with the idea of being an alternative to the Star series of solid kick motor stage, (ex., Star 48).

\footnotetext{
${ }^{1}$ Research Scientist I, Center of Space Nuclear Reserach, 995 University Blvd., Idaho Falls, ID 83401, Professional.

${ }^{2}$ Graduate Student, Astronautical Engineering, University of Southern California, 854B Downey Way LA, CA 90089-1192, Student Member.
} 


\section{Concept Energy Source}

The concept will utilize decay energy from radioisotopes. However, if the radioisotope's specific power can be enhanced where thermal energy can be accumulated over time to making energy available for a short time period then the RTR concept is possible. $\mathrm{Pu}$ has $1.6 \times 10^{\wedge} 6 \mathrm{MJ} / \mathrm{kg}$ (thermal) compared to roughly $10 \mathrm{MJ} / \mathrm{kg}$ for chemical propellants. Hence the proposed radioisotope is ${ }^{238} \mathrm{PuO}_{2}$. It has heritage use within NASA, high specific energy: $1.6 \times 10^{6} \mathrm{MJ} / \mathrm{kg}$ (thermal). Energy comparison between a RTG and Li-ion is $9.6 \times 10^{4} \mathrm{MJ} / \mathrm{kg}(6 \%)$ vs Li-ion: $0.72 \mathrm{MJ} / \mathrm{kg}$ (electric). However ${ }^{238} \mathrm{PuO}_{2}$, has a very poor specific power of 0.392 $\mathrm{W} / \mathrm{g}$. Hence to improve this performance, fuel containment is carried out by encapsulating the fuel. The fuel is encapsulated in a tungsten-basd matrix that provides high strength and toughness. It also provides great energy density. Figure 1 below shoes fabricated tungsten-cermet fuel pellets.

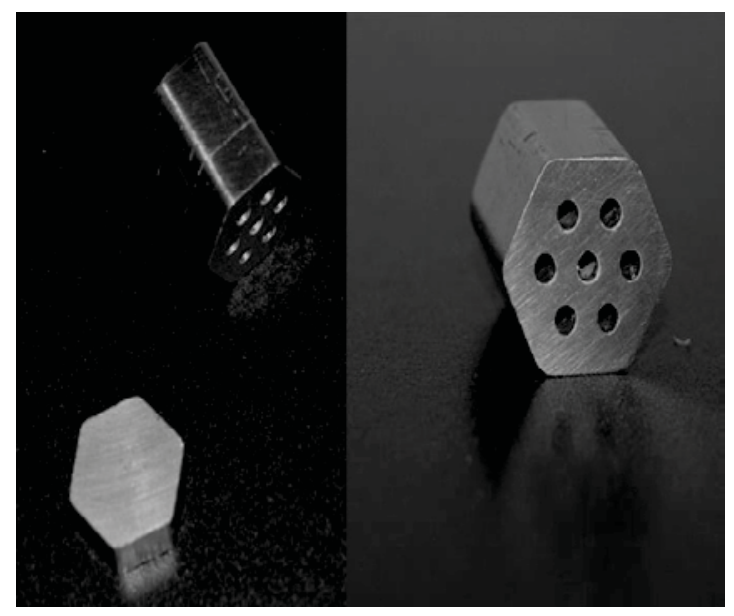

Figure 1 - Tungsten based Cermet fuel [1]

\section{Approach}

The proposed radioisotope-based system would leverage the high specific energies $[\mathrm{J} / \mathrm{kg}]$ associated with radioisotope materials and enhance their inherent low specific powers [W/g]. This is accomplished by accumulating thermal energy from nuclear decay within a central core over time. This allows for significant amounts of power to be transferred to a flowing gas over short periods of time. In the proposed configuration the stored energy can be utilized in two ways (see Figure 5): (1) with direct propellant injection to the core, the energy can be converted into thrust through the use of a converging-diverging nozzle and (2) by flowing a working fluid through the core and subsequent Brayton engine, energy within the core can be converted to electrical energy. The first scenario achieves moderate ranges of thrust, but at a higher Isp than traditional chemical-based systems. The second scenario allows for the production of electrical power, which is then available for electric-based propulsion. Additionally, once at location the production of electrical power can be dedicated to the payload's communication system for data transfer. Ultimately, the proposed dual-mode propulsion platform capitalizes on the benefits of two types of propulsion methods - the thrust of thermal propulsion ideal for quick orbital maneuvers and the specific impulse of electric propulsion ideal for efficient inter-planetary travel. The significant advantage of using radioistopes are the provide continuous energy for many years. Also the thermal energy from the radioisotopes can be utilized in multiple ways. Figure $\mathbf{2}$ in the next page shows an artistic rendering of the concept in Earth orbit.

\section{A. Thermal Capacitor Qualifications}

The core material must meet a few needed qualifications in order to store the thermal energy and then dissipate it to a flowing gas. In this capacity the core is therefore acting like a thermal capacitor. Based on material selection and reasonable latent heat of fusion, thermal storage can be accomplished. Therefore to qualify for a thermal capacitor the following attributes are required -

1) High thermal storage, high thermal conductivity and high melting temperature. 
2) Sensible heat based on a material's heat capacity.

3) Latent heat based on energy needed to change a material's phase.

\section{B. Core Material}

Silicon is identified as a suitable material. The latent heat of fusion of Silicon is $\Delta H_{\text {fusion }}=1.8 \mathrm{MJ} / \mathrm{kg}$ and the melting temperature of Silicon is $T_{\text {melt }}=1687 \mathrm{~K}$. This would allow for an operational temperature of around $1700 \mathrm{~K}$. Figure 3 below shows the conceptual artistic rendering of propulsion system (left) and main engine (right).

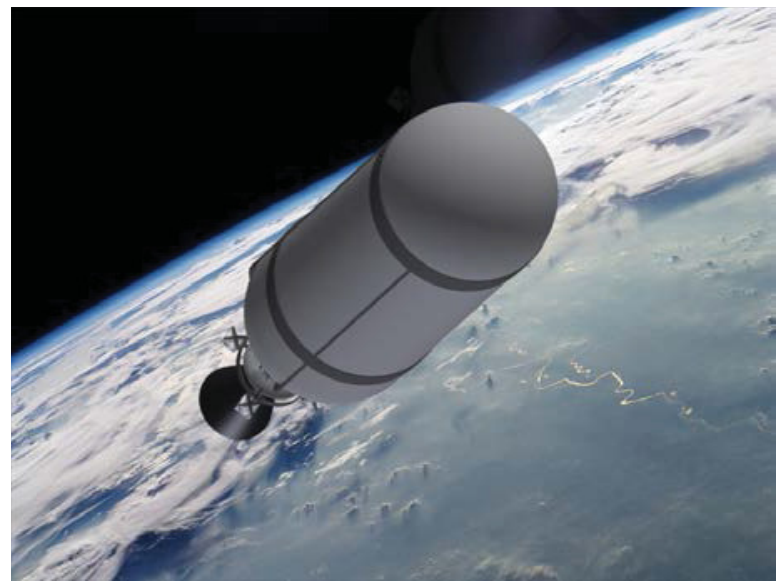

Figure 2 - Artistic rendering of the concept in earth orbit.
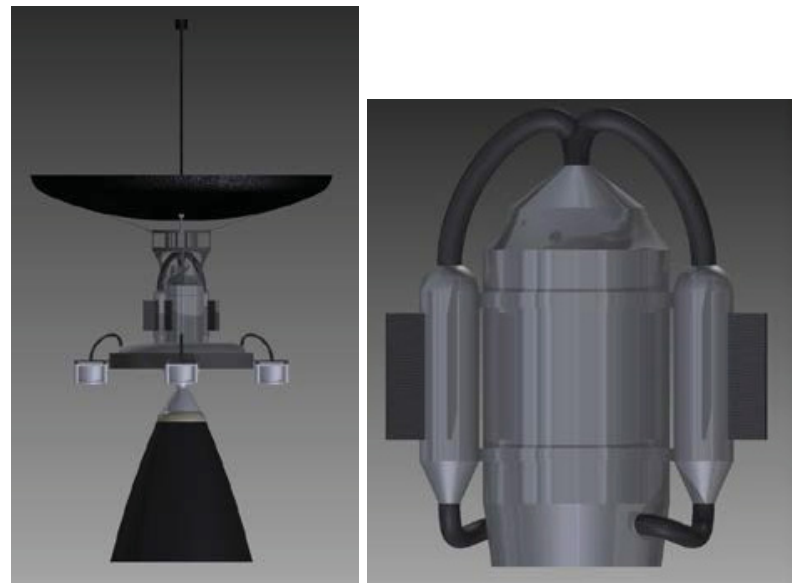

Figure 3: conceptual artistic rendering of propulsion system (left) and main engine (right).

\section{Concept of operations}

At the center of the propulsion system is the radioisotope fuel. In this study ${ }^{238} \mathrm{PuO}_{2}$ will be used to provide the decay energy. For safety and retention, the fuel will be encapsulated within a tungsten-based matrix [1,4]. The resulting fuel rods will be integrated within a central core material. The ideal core material must be capable of storing thermal energy, i.e., thermal capacitor, and then dissipating that energy to a flowing gas. Several materials have been identified elsewhere as being capable of achieving this task relying on their specific heat capacities, e.g., beryllium and boron tetra-carbide [1]. Instead, in this study the use of silicon as a thermal capacitor material is being considered. Silicon undergoes a latent heat of fusion $(\Delta \mathrm{H}=50.2 \mathrm{~kJ} / \mathrm{mol})$ at $1685 \mathrm{~K}$ [5]. By taking advantage of silicon's latent heat of fusion, when gas is flowed through the silicon core a phase transformation from liquid to solid occurs. This in turn, will dissipate energy from the core to the gas at a constant core outlet temperature, yielding a constant chamber temperature or turbine inlet temperature depending on mode being used. For heat rejection, turbine exhaust gases will be passed through flow channels in a solid lithium block. Having a high heat capacity, the lithium block absorbs the thermal energy from the gas, which is then allowed to dissipate slowly between pulses. This method has the potential to deliver a low mass, compact heat rejection subsystem [2].

So the first mode is the direct propellenat heating mode which provides the thermal based propulsion. Heated propellant is expelled through the nozzle creating thrust. Figure $\mathbf{5}$ illustrates that. The second mode is the energy conversion mode where a closed loop Brayton cycle which can produce 10's of $\mathrm{kW}$ per pulse and multiple pulses per day. Figure 5 also illustrates that. Figure $\mathbf{4}$ in the next page, shows the proposed regeneration cycle process bringing clarity to the understanding of the entire operation of the propulsion system as one entity. 

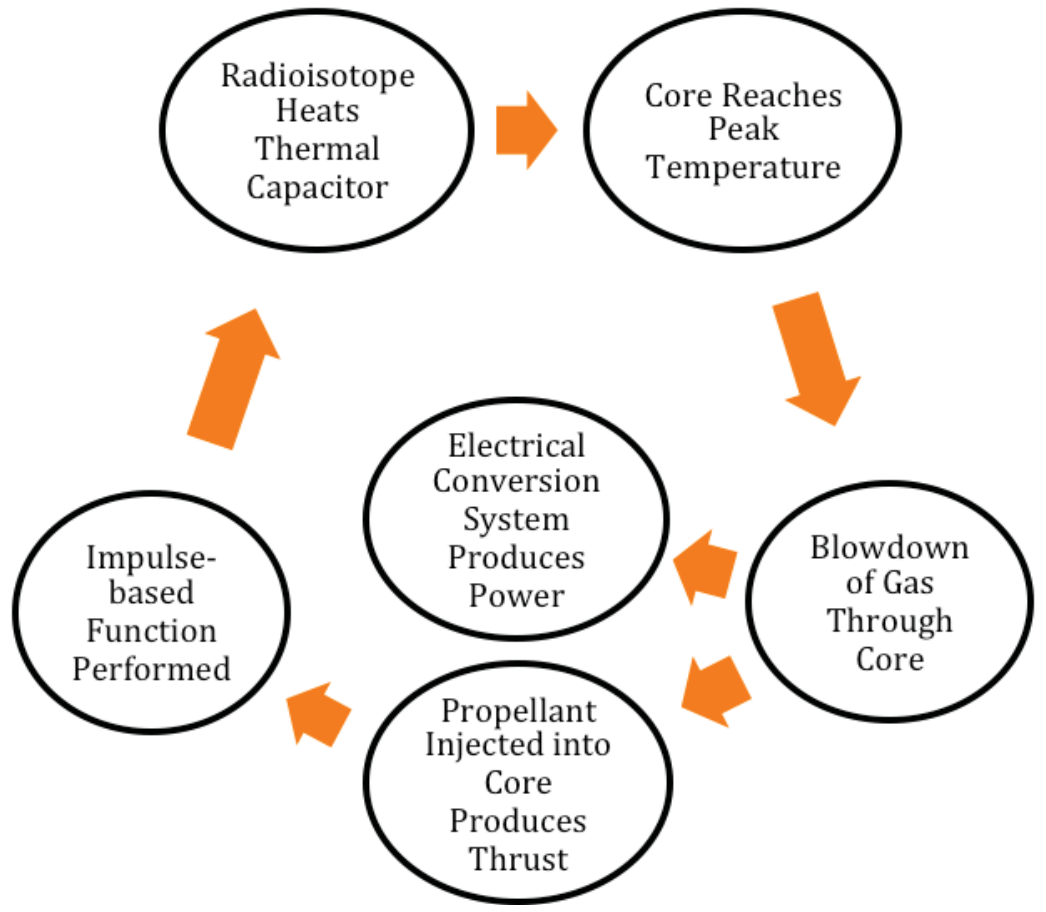

Figure 4 - Proposed Renegration Cycle Process

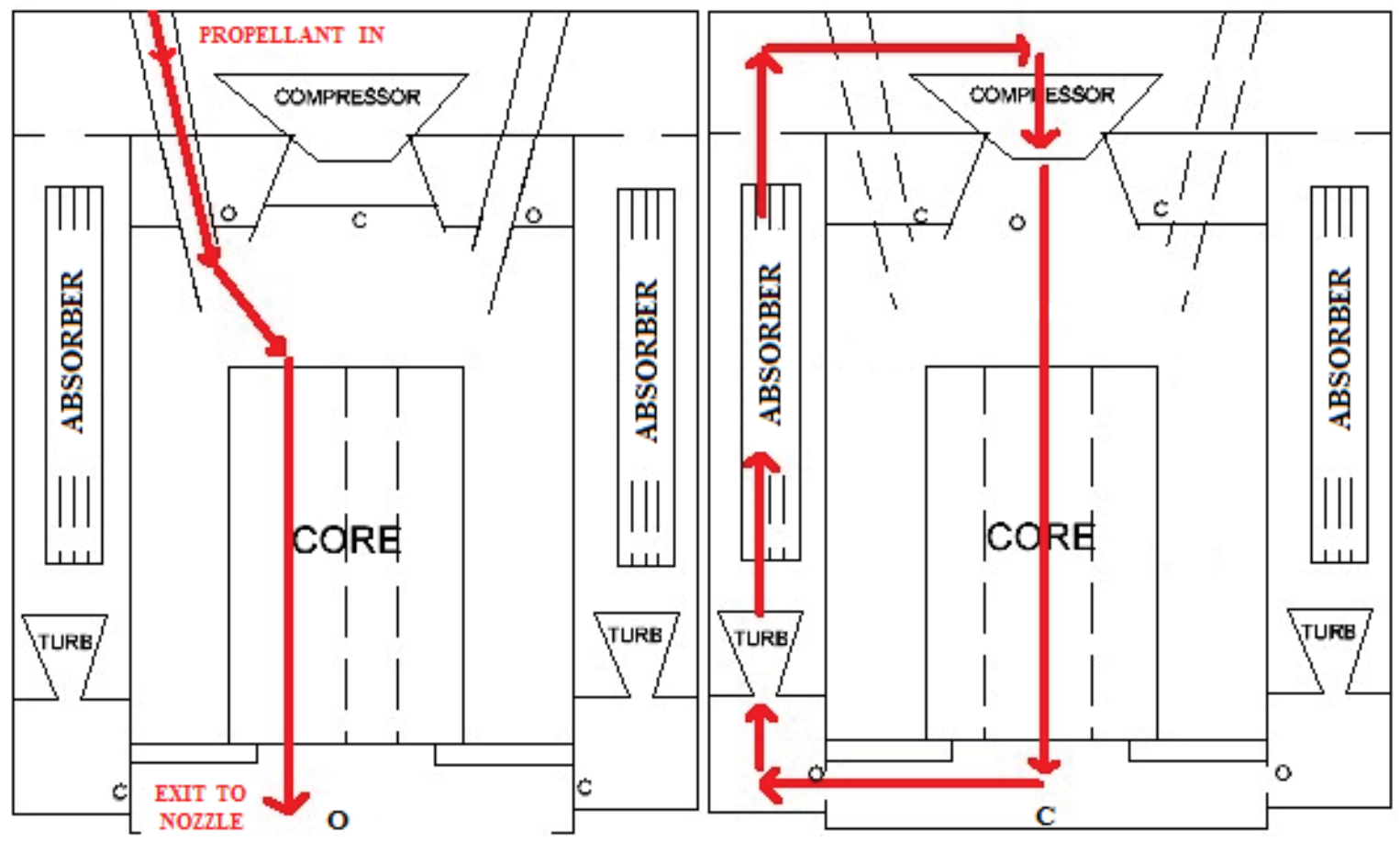

Figure 5 - Diagram showing the fluid flow for both the thermal (left) and electric (right) modes of the system.

The dual mode functionality is a very attractive aspect of this concept. Propellant is directly heated increasing its temperature and pressure and then expelled through a converging / diverging nozzle to impart momentum on the system. 


\section{Performance}

Performance based on preliminary results, based on Earth escape.

\section{Operation}

time $_{\text {blowdown }}: 360 \mathrm{~s}$

time $_{\text {heatup: }} 0.2$ day

time $_{\text {escape: }} 80$ days

$\Delta V_{\text {escape }}: 3.8 \mathrm{~km} / \mathrm{s}$

temp: $1700 \mathrm{~K}$

\section{Core}

$30 \mathrm{~cm}$ length

$20 \mathrm{~cm}$ diameter

$2 \mathrm{~mm}$ dia. flow channels

$18.1 \mathrm{~kg}$ Silicon

$7.16 \mathrm{~kg}^{238} \mathrm{PuO}$

$89.8 \mathrm{~kW}_{t}$ core power

$27 \mathrm{~kW}$ electric power

$31.1 \mathrm{~kg}$ TOTAL

\section{Performance}

propellant: Hydrogen

Isp : $694 \mathrm{~s}$

blowdowns: 400

$\Delta V_{\text {per burn }}: 0.0095 \mathrm{~km} / \mathrm{s}$

thrust $_{\text {per burn }}: 26.39 \mathrm{~N}$

prop. mass per burn: $1.39 \mathrm{~kg}$

prop. mass: $\sim 558 \mathrm{~kg}$ TOTAL

Figure 6 - Artistic rendering of the propsosed concept.
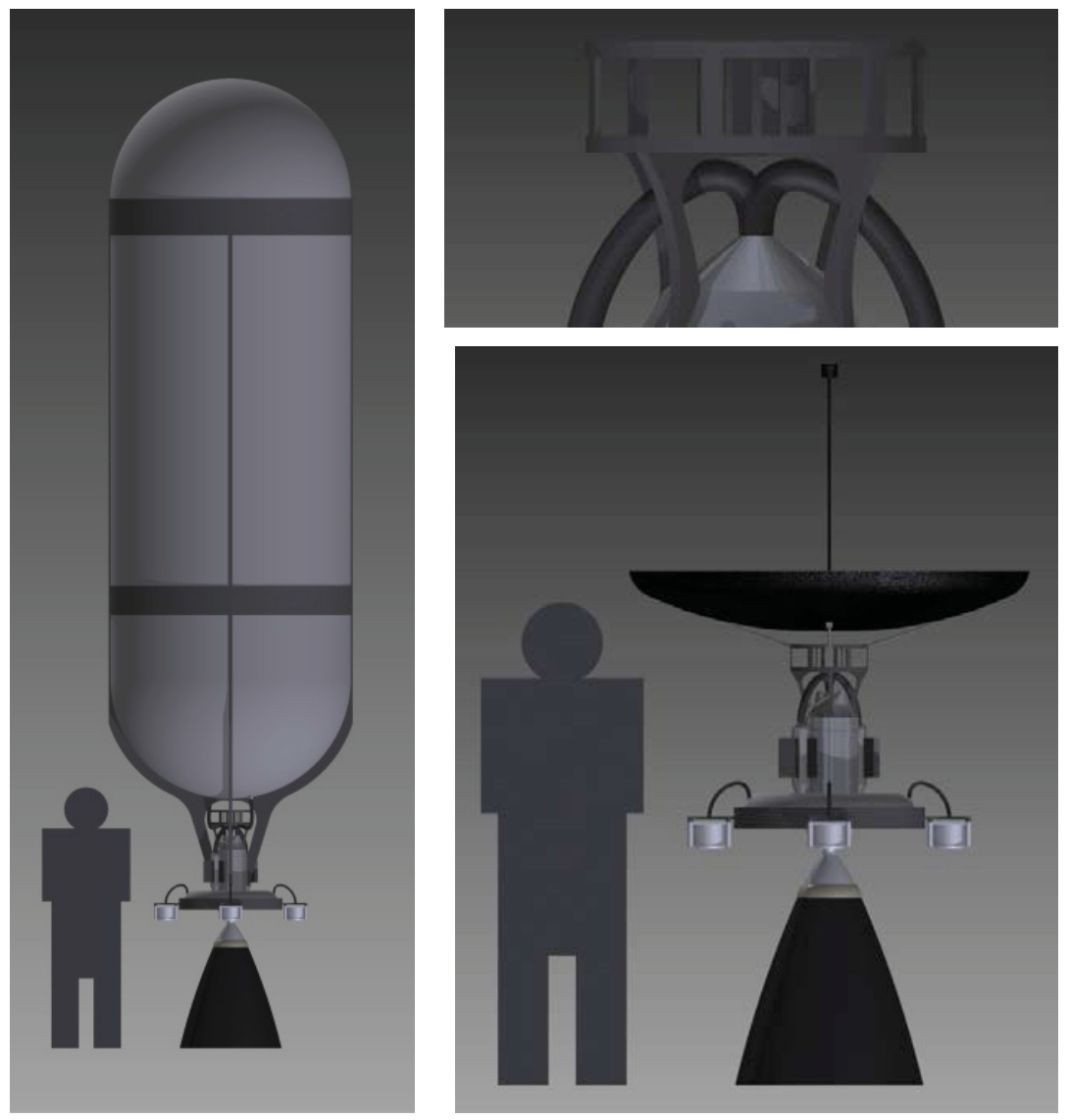

\section{Core optimization}

Thermal interactions within the core
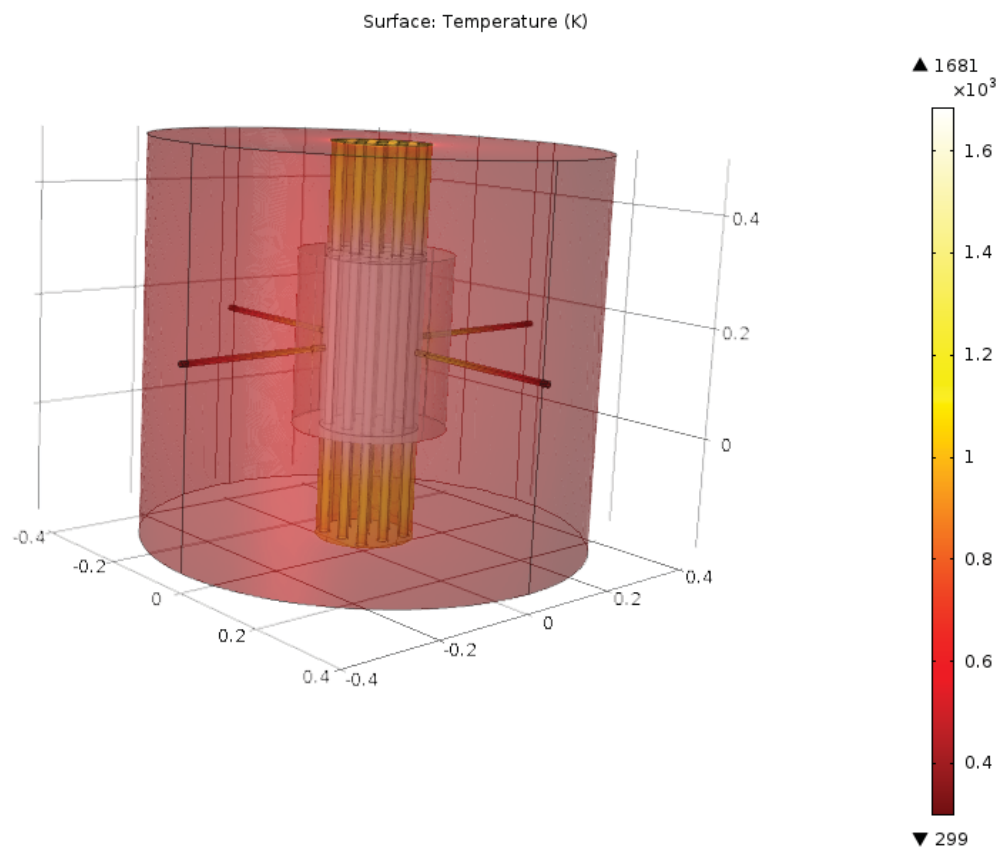
details core sizing such as isotope loading, capacitor size, insulation, etc. Thermal hydraulics between the core and flowing gas details performance of propellant yielding chamber pressure \& temperature aiding in nozzle development. It also details performance of working fluid for energy conversion to help determine power generation and efficiencies. To gain a better understanding of the thermal hydraulics and heat transfer amongst the various components of the core a COMSOL model was created to optimize the core sizing.

Figure 7. COMSOL model of the core. 


\section{VI.Mission Design Instrumentation and Communication}

\section{Proposed Instrumentation Package}

A key aspect of this phase I study is the development of a mission design that includes determining potential instruments to be included within the payload enevelope. The instrumentation package has been designed for a $6 \mathrm{U}$ CubeSat payload.

$\begin{array}{llll}\text { Instrument } & \text { Mass (g) } & \left.\text { Volume } \mathbf{( c m}^{3}\right) & \text { Power (W) } \\ \text { Thermal Imaging Radiometer } & 1,000 \text { 's } & 1,000 \text { 's } & 10 \text { 's } \\ \text { Infrared Spectrometer } & 100 \text { 's } & 100 \text { 's } & - \\ \text { High Resolution Camera (MAC) } & 100 \text { 's } & 100 \text { 's } & 1 \text { 's } \\ \text { Mass Spectrometer } & 100 \text { 's } & 10 \text { 's } & 1 \text { 's }\end{array}$

\section{E. Communication link budget}

The communication link budget is designed for a $8.48 \mathrm{AU}$ distance which is the closest / best scenario. The receiving ground station antenna is considered to be DSN's $34 \mathrm{~m}$ antenna. The link budget assumes a very good pointing accuracy of the antenna. Figure 8, shows the rendered CAD model of the transmitting antenna from s/c.

\begin{tabular}{c|c|c|c} 
Item & Symbol & Units & Value \\
$\begin{array}{c}\text { Frequency } \\
\text { Transmission Power }\end{array}$ & Pt & Watts & 25000 \\
$\begin{array}{c}\text { Transmission } \\
\text { Antenna Dia. }\end{array}$ & Dt & m & 1.5 \\
$\begin{array}{c}\text { Trans. Antenna Gain } \\
\text { (net) }\end{array}$ & Gt & dBi & 50.16 \\
$\begin{array}{c}\text { Prop. Path Length } \\
\text { Space Loss }\end{array}$ & S & km & $1.27 \mathbf{e}^{9}$ \\
System Noise Temp. & Ts & KB & $-\mathbf{3 0 3 . 3 0}$ \\
Data Rate & R & Mbps & $\mathbf{8 4 . 1 0}$ \\
SNR & Eb/No & - & 5.94
\end{tabular}




\section{VII.Initial Trajectory Analysis}

The trajectory of the spacecraft can be categorized into two sections:

1. Thermal Propulsion mode: Provides high thrust and moderate Isp. Impulse thrusting allows for phasing maneuvers (perigee pmping) to achive Earth escape.

2. Electric Propulsion mode: Provides high Isp for interplanetary cruise travel. This mode allows for shortet transmit time and suppot for $2.2 \mathrm{~kW}$ Hall Effect thrusters. Figure 9 below shows an AeroJet BPT-2000 Hall Effect thruster which can be a potential candidate for this system.

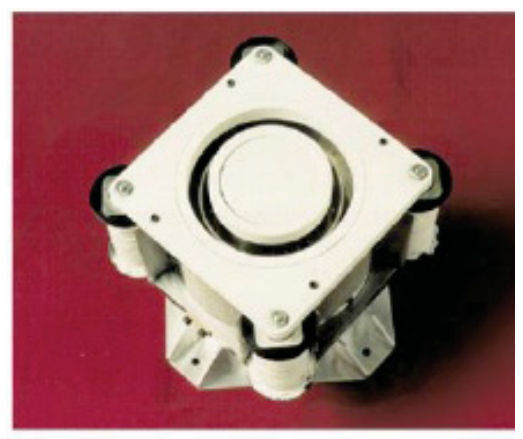

Figure 9: Aerojet BPT-2000 Hall Effect thruster.

An important aspect of developing the mission architecture is to perform adequate trajectory analysis in order to reach at the target destination. It also allows to use each propulsion mode to its full potential. For transfer to Enceladus from Saturn orbit techniques have been laid out in the Enceladus-based missions from the Decadal survey which include multiple flybys of several other Saturnian moons. Access to a new trajectory optimization tool called the Evolutionary Mission Trajectory Generator or EMTG that was developed by Jacob Englander of Goddard, was used to estimate some preliminary trajectories. Currently an appropriate tracjectory between Earth to Saturn has been evaluated and EMTG is being used to optimize the entire journey length to Enceladus. The trajectory information to rendevouz Saturn from Earth has been laid out below. Figure 10 shows the 2-D trajectory map.

\section{$\underline{\text { Earth - Jupiter - Saturn }}$}

- $\quad$ Earth Departure: Jan-18-2018

- Saturn Arrival: July-11-2023

- Total Duration: $\mathbf{5 . 4 8}$ years

- Injection $\Delta \mathrm{V}\left(\right.$ Earth $\left._{\text {escaped }}\right): 6.42 \mathrm{~km} / \mathrm{s}$

- Jupiter Gravity Assist: 0.12 km/s

- Post Injection $\Delta \mathrm{V}\left(\operatorname{Saturn}_{\text {capture }}\right): \mathbf{0 . 5 4} \mathbf{~ k m} / \mathbf{s}$

Total $\Delta \mathrm{V}$ required by propulsion system $=\mathbf{6 . 9 6} \mathbf{~ k m} / \mathbf{s}$

Figure $\mathbf{1 1}$ below shows an artic rendering of concept in Enceladus.

Figure 10: Earth to Saturn Trajectory with Jupiter flyby [6].
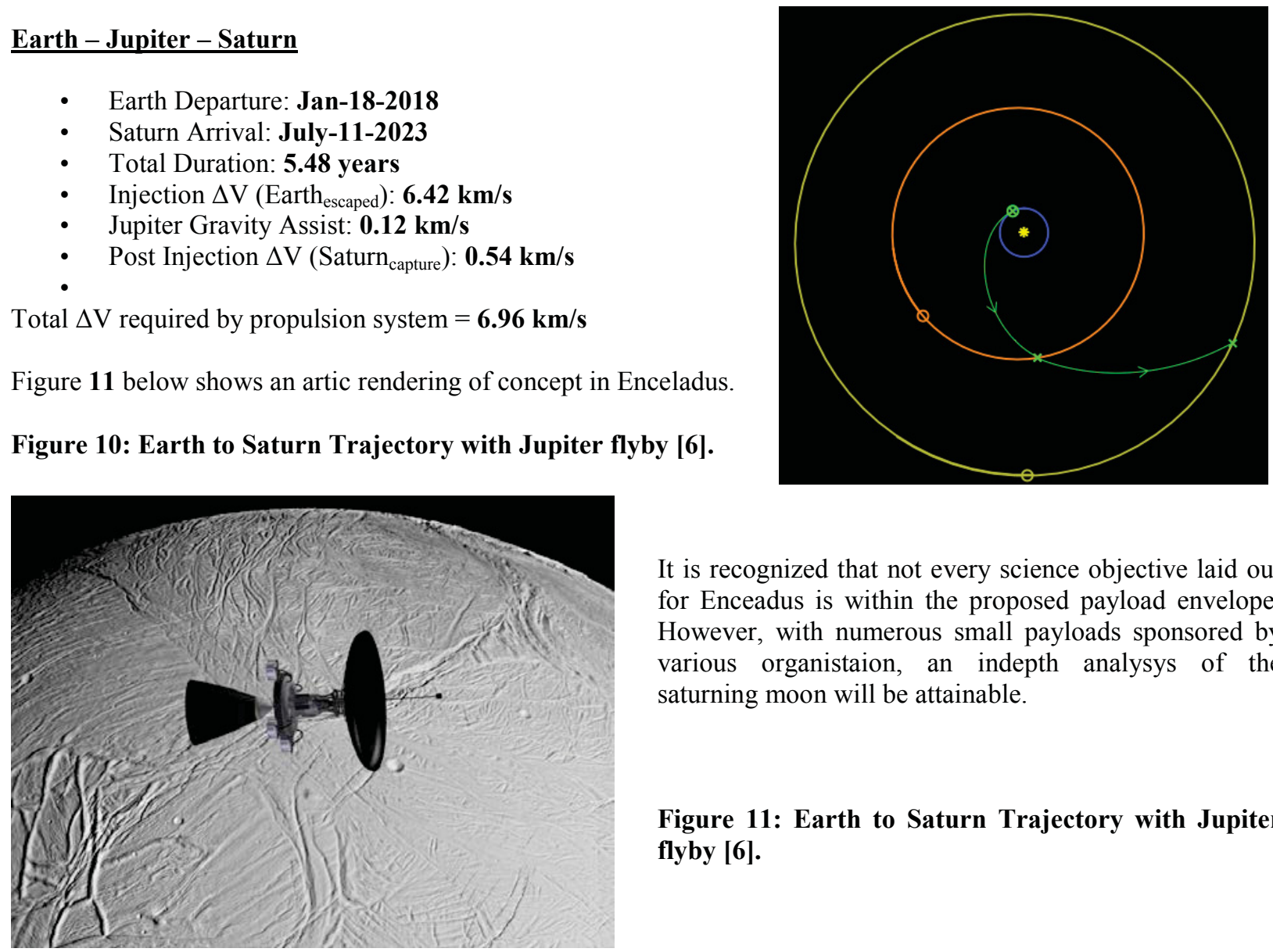

It is recognized that not every science objective laid out for Enceadus is within the proposed payload envelope. However, with numerous small payloads sponsored by various organistaion, an indepth analysys of the saturning moon will be attainable.

Figure 11: Earth to Saturn Trajectory with Jupiter flyby [6]. 
VIII. Conclusion

The work presented in this paper is for a NIAC Phase 1 submission. A concept and mission design was estalished. Elementary (basic) thermal hydraulics and trajectory optimization simulation has been achieved. Future works involves detailed concept optimization, new (Silicon) technology demonstration of energy storage within thermal capacitor, energy conversion with closed - loop Brayton cycle and thrust demonstration with propellant nozzle. Adjacent Figure 12, shows some available experimentation hardware at the CSNR.
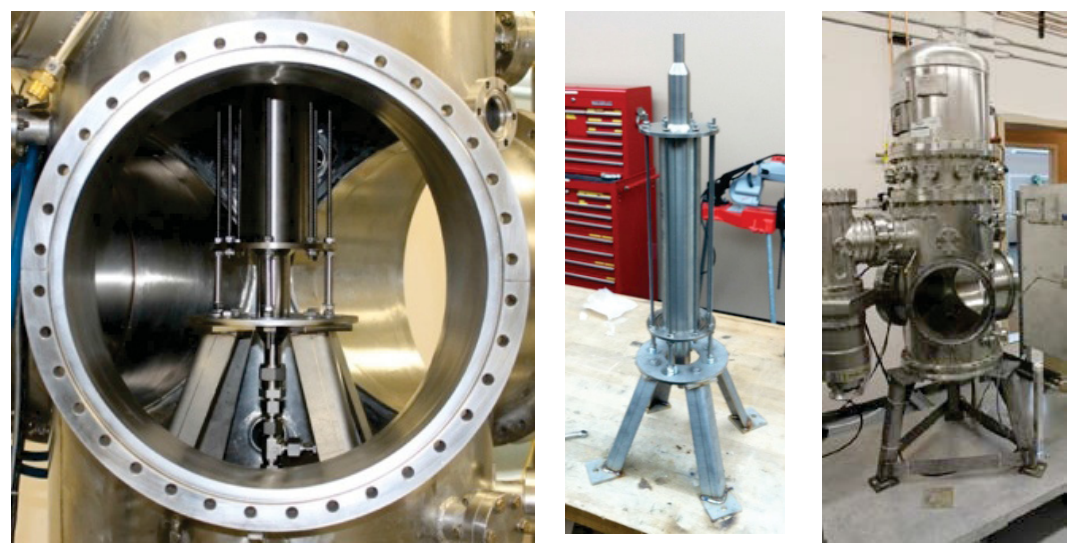

Figure 12 - Available Experimentation Hardware

\section{Acknowledgments}

1. Funding Provided By: NASA NIAC Phase I Award.

2. Dr. Robert O'Brien, CSNR fuel encapsulation contributions.

3. Dr. Carl Stoots, Idaho National Laboratory - RTPV contributions.

4. William Taitano, CSNR Modeling contributions

\section{References}

[1] O'Brien R. C., Ambrosi R. M., Bannister, N. P., et al., Spark Plasma Sintering of simulated radioisotope materials within tungsten cermets, Journal of Nuclear Materials, 2009, 393(1), 108-113.

[2] O'Brien R. C., Ambrosi R. M., Bannister, N. P., et al., Safe radioisotope thermoelectric generators and heat sources for space applications, Journal of Nuclear Materials, 2008, 377(3), 506-521.

[3] Mattarolo, G., "Development and Modeling of a Thermophotovoltaic System," Thesis, Electrical Engineering and Computer Science Dept., University of Kassel. Kassel, Germany (2007).

[4] Carl M. Stoots. "Emissivity Tuned Emitter For RTPV Power Sources." Nuclear and Emerging Technologies For Space, The Woodlands, TX, 03/21/2012,03/23/2012. (2012).

[5] Larson W. J., Wertz J.R., Space Mission Analysis and Design, $3^{\text {rd }}$ Edition, Microcosm Press, 2005.

[6] Curtis H. D., Orbital Mechanics for Engineering Students, Elsevier Aerospace Engineering Series, 2005, pg. 268-273.

[7] Gaskell, D. R. Intro. to the Thermodynamics of Materials, $4^{\text {th }}$ Ed. (2003) 587.

[8] Kelley, K. K. "The Specific Heats at Low Temperatures Of Crystalline Boric Oxide, Boron Carbide And Silicon Carbide". Journal of the American Chemical Society. 63 (1941) 1137-9.

[9] Kantor, K., P. B. Krasovitskaya, R. M. Kisil, O. M. Fiz. "Determining The Enthalpy And Specific Heat Of Beryllium In The Range 600-2200" Phys. Metals and Metallog. 10 (6) (1960) 42-4. Mcl-905/1, Ad-261792.

[10] Booker, J. Paine, R. M. Stonehouse, A. J. Wright. "Investigation Of Intermetallic Compounds For Very High Temperature Applications". Air Development Division (1961) 1-133. Wadd Tr 60-889, Ad 265625.

[11] Pankratz, L. B. K. K. Kelley. Thermodynamic Data for Magnesium Oxide U S Bur Mines. Report. 1-5 (1963); Bm-Ri-6295.

[12] Kandyba, K., V. V. Kantor, P. B. Krasovitskaya, R. M. Fomichev, E. N. Dokl "Determination Of Enthalpy And Thermal Capacity Of Beryllium Oxide In The Temperature Range From 1200 - 2820" Aec-Tr-4310. (1960) 14.

[13] Hedge, J. C., J. W. Kopec, C. Kostenko, J. I. Lang. Thermal Properties Of Refractory Alloys. Aeronautical Systems Division. (1963) 1-128; ( Asd-Tdr-63-597, Ad 424375 )

[14] X-123CdTe (X-Ray \& Gamma-Ray Detector System) - http://www.amptek.com/x123cdte.html

[15] Argus Infrared Spectrometer - http://www.thoth.ca/spectrometers.htm

[16] NanoCam C1U (High Resolution Camera) - http://gomspace.com/index.php?p=products-clu

[17] Low Voltage Gated Electrostatic Mass Spectrometer (LVGEMS) -

http://www.techbriefs.com/component/content/article/16137 